\title{
Thiopurine Methyltransferase Genotype and Phenotype Status in Japanese Patients with Systemic Lupus Erythematosus
}

\author{
Yuko OKadA, ${ }^{a}$ Katsunori NaKamura,${ }^{a}$ Tomoko Kodama, ${ }^{b}$ Kazue Ueki, ${ }^{c}$ Yoshito TsuKadA, ${ }^{c}$ \\ Akira MaEzawa, ${ }^{c}$ Norifumi Tsukamoto, ${ }^{c}$ Yoshihisa NoJima, ${ }^{c}$ Takashi IshizaKi,${ }^{d}$ \\ Ryuya HoriUCHI, ${ }^{a, b}$ and Koujirou YAMAMOTO ${ }^{*, a, b}$ \\ ${ }^{a}$ Department of Clinical Pharmacology, Gunma University Graduate School of Medicine; ${ }^{b}$ Department of Pharmacy, \\ Gunma University Hospital; ' Department of Medicine and Clinical Science, Gunma University Graduate School of \\ Medicine; Maebashi, Gunma 371-8511, Japan: and ${ }^{d}$ Department of Clinical Pharmacology and Pharmacy, School of \\ Pharmaceutical Sciences, Teikyo-Heisei University; Ichihara, Chiba 290-0193, Japan.
}

Received May 4, 2005; accepted September 5, 2005; published online 9, 2005

\begin{abstract}
We investigated the genotypic status of thiopurine methyltransferase (TPMT) polymorphism to evaluate the possible risk of the toxicity of azathioprine (AZA) in 68 patients with systemic lupus erythematosus (SLE). The allele frequency of TPMT mutation in the SLE group (2.9\%) was higher than that in 174 Japanese healthy volunteers $(1.1 \%)$, although it did not reach statistically significant difference $(p=0.23)$. The mean value of TPMT activities in 51 subjects with $T P M T^{*} 1 / * 1$ was $40 \%$ higher than that of 4 subjects with $T P M T * 1 / * 3 C$ in SLE group $(18.1 \pm 6.1 \mathrm{nmol} / \mathrm{h} / \mathrm{ml}$ packed red blood cells $(\mathrm{pRBC})$ versus $13.2 \pm 3.2 \mathrm{nmol} / \mathrm{h} / \mathrm{ml} \mathrm{pRBC} ; p=0.11)$. Two out of 4 SLE patients with $T P M T^{*} 1 / * 3 C$ had been treated with AZA, and one patient showed a leucopenia. The TPMT genotyping before AZA treatment is recommended for Japanese SLE patient group to avoid the AZA-induced adverse events, although detection of the patient with low TPMT activity by genotyping is still imperfect.
\end{abstract}

Key words thiopurine methyltransferase; systemic lupus erythematosus; pharmacogenetics

Thiopurine methyltransferase (TPMT) catalyses the Smethylation in azathioprine (AZA), thioguanine and 6-mercaptopurine (6-MP). ${ }^{1,2)}$ The low TPMT activity in erythrocytes has been associated with an increased risk of severe and potentially fatal hematopoietic toxicity caused by the accumulation of the cytotoxic metabolites of thiopurine drugs. ${ }^{3-6)}$

Genetic polymorphism of the TPMT activity in human was first reported by Weinshilboum and Sladek. ${ }^{7}$ Four variant TPMT alleles, TPMT*2 (G238C), TPMT*3A (G460A, A719G), TPMT*3B (G460A) and $T P M T^{*} 3 C$ (A719G), were detected in over $80 \%$ of Caucasian individuals with intermediate metabolizers or poor metabolizers. ${ }^{8}{ }^{8}$ The TPMT activity of one subject with $T P M T^{*} 1 / * 3 C$ was $40 \%$ lower than the mean value of TPMT activities in 44 Japanese subject. ${ }^{9)}$ In the yeast expression system, TPMT activities of $T P M T^{*} 2$, $T P M T^{*} 3 A, T P M T^{*} 3 B$ and $T P M T^{*} 3 C$ mutant alleles showed 1.4-100 fold lower than that with the wild-type, respectively. ${ }^{10,11)}$ These results suggested that the genetic polymorphism is a major determinant of the TPMT activity.

On the other hand, Decaux et al. ${ }^{12)}$ measured significantly lower TPMT activity in 53 women with SLE when compared with 30 healthy control participants but not with 28 patients with other dysimmune diseases. The allele frequency of TPMT mutation in SLE patients however, have not been reported in any of the TPMT pharmacogenetic studies.

Based upon the background knowledge as discussed above, we intended to assess the genotype status of TPMT in a group of Japanese SLE patients who may undergo a therapy of AZA, a substrate drug, toward TPMT.

\section{MATERIALS AND METHODS}

DNA Samples All of the study subjects included herein were Japanese by birth and lineage. The demographic char- acteristics of the subjects are summarized in Table 1. The study samples consisted of 68 patients with SLE in Gunma University Hospital (men: women=7:61) and 174 healthy volunteer subjects (men : women $=98: 76$ ). All subjects in the SLE group fulfilled 1982 revised criteria of American Rheumatology Association for the classification of SLE. ${ }^{13)}$ DNA analysis was approved by the institutional review board for clinical trials at Gunma University Hospital. Written informed consent was obtained from each participant after being informed of the experimental procedure and the purpose of the study. DNA reference samples with $T P M T^{*} 1 / * 2$ and $T P M T^{*} 3 A / * 3 A$ were kindly provided by Dr. Richard Weinshilboum, Mayo Medical School (Rochester), and $T P M T * 2 / * 2$ and $T P M T * 1 / * 3 A$ were provided by Dr. William Evans, St. Jude Children's Hospital (Memphis).

Determination of TPMT Genotype Genomic DNA was extracted from whole blood using a QIAamp ${ }^{\circledR}$ Blood Kit (QIAGEN, U.S.A.). DNA was resuspended in $100 \mu \mathrm{l}$ of TE buffer $(10 \mathrm{~mm}$ Tris, $1 \mathrm{~mm}$ ethylenediamine tetraacetic acid, $\mathrm{pH}$ 8.0) and stored at $4{ }^{\circ} \mathrm{C}$.

The presence of G460A (TPMT*3A and TPMT*3B), A719G $\left(T P M T^{*} 3 A\right.$ and TPMT*3C) and G238C (TPMT*2) mutations was detected according to the method of Yates et $a l^{8)}$ with minor modifications. In brief, the amplification reaction was carried out in a total volume of $50 \mu \mathrm{l}$ in the presence of $100 \mathrm{ng}$ of DNA, $50 \mathrm{~mm}$ Tris- $\mathrm{HCl}$ (pH 8.3), $50 \mathrm{~mm}$ $\mathrm{KCl}, 1.5 \mathrm{~mm} \mathrm{MgCl}, 0.01 \%$ (w/v) gelatin, $0.5 \mu \mathrm{M}$ each primer and $2 \mathrm{U}$ AmpliTaq Gold ${ }^{\mathrm{TM}}$ DNA polymerase (Applied

Table 1. Characteristics of the Patients with SLE and the Control Subjects

\begin{tabular}{lrc}
\hline \hline \multicolumn{1}{c}{ Study group } & $n$ & Age range (mean) \\
\hline SLE patients & 68 & $14-76(39.8)$ \\
Healthy volunteer (control) & 174 & $21-57(25.4)$ \\
\hline
\end{tabular}


Biosystems, U.S.A.). The PCR products were digested with $M w o$ I at $60^{\circ} \mathrm{C}$ for $2 \mathrm{~h}(\mathrm{G} 460 \mathrm{~A})$ or $A c c$ I at $37^{\circ} \mathrm{C}$ for $2 \mathrm{~h}$ $(\mathrm{A} 719 \mathrm{G})$, and the DNA fragments were separated on $2.5 \%$ agarose gel.

The G238C mutation (TPMT*2) was analyzed using an allele specific PCR ${ }^{8)}$ DNA fragment was amplified in the presence of $100 \mathrm{ng}$ of genomic DNA, $50 \mathrm{~mm}$ Tris- $\mathrm{HCl}(\mathrm{pH} 8.3)$, $50 \mathrm{~mm} \mathrm{KCl}, 3.5 \mathrm{~mm} \mathrm{MgCl}{ }_{2}, 0.01 \%$ (w/v) gelatin, $0.5 \mu \mathrm{M}$ each primer and $1 \mathrm{U}$ AmpliTaq Gold ${ }^{\mathrm{TM}}$ DNA polymerase. The PCR protocol was the same as described for the detection of G460A mutation. The DNA fragments were separated on $2.5 \%$ agarose gel.

Determination of TPMT Activity Venous blood samples were collected from 55 patients with SLE. Red cells were prepared as described previously. ${ }^{14)}$ Briefly, $5 \mathrm{ml}$ of whole blood collected in heparinized tubes was centrifuged at $800 \mathrm{~g}$ for $10 \mathrm{~min}$ at $4{ }^{\circ} \mathrm{C}$ to isolate red cells. After washing the pellet twice with $3 \mathrm{ml}$ of normal saline and centrifuged at $800 \mathrm{~g}$, cells were gently resuspended in $2 \mathrm{ml}$ of saline and the haematocrit was determined. After this step, the results of the assay can be expressed in terms of milliliters of packed red blood cells ( $\mathrm{pRBC}$ ). Red cells were lysed with cold distilled water ( $4 \mathrm{ml}$ for $1 \mathrm{ml}$ of solution) and centrifuged $(13000 \boldsymbol{g}$, $\left.10 \mathrm{~min}, 4^{\circ} \mathrm{C}\right)$. The supernatant was kept at $-80^{\circ} \mathrm{C}$ until analysis. TPMT is stable for several months under these conditions.

TPMT activity was determined by measuring the 6-methyl mercaptopurine (6-MMP) formed in the enzymatic reaction. The assay was performed as previously described ${ }^{15)}$ with minor modifications. The assay has been performed in a total volume of $600 \mu \mathrm{l}$. The final concentrations of 6-MP, $S$-adenosyl-L-methionine, dithiothreitol (DTT) and alloprinol were $3 \mathrm{mmol} / 1,25 \mu \mathrm{mol} / 1,5 \mathrm{mmol} / 1$ and $25 \mu \mathrm{mol} / 1$, respectively. The reaction was stopped after $1.5 \mathrm{~h}$ by addition of hydrochloric acid (1 M) $100 \mu 1$.

After incubation phase, a liquid-liquid extraction was performed as previously described. ${ }^{16)}$ Procedures of HPLC were similar to those previously described. ${ }^{17)}$ The analytical column was a Tosoh TSK-GEL, ODS-80Tm $(250 \times 4.6 \mathrm{~mm})$, the mobile phase of water-acetonitrile-triethylamine-DTT (92.7:7:0.2:0.1, v/v) was adjusted to $\mathrm{pH} 3.2$ with orthophosphoric acid and pumped at a flow-rate of $1.0 \mathrm{ml} / \mathrm{min}$. The detection wavelength was $290 \mathrm{~nm}$.

The enzyme activity was expressed as international units (nmol 6-MMP formed per hour) per milliliter of pRBC.

Statistical Analysis The statistical significance of the differences in genotype between the two populations was determined using Fisher's exact test.

\section{RESULTS}

Heterozygote $\left(T P M T^{*} 3 C\right)$ individuals were detected in 4 of the SLE group $(n=68)$ and 4 of the control group $(n=174)$. Neither G238C nor G460A mutation was detected in any subject enrolled in this study. Among the 68 patients in the SLE group, the allele frequencies of $T P M T^{*} 2$, $T_{P M T}^{*} 3 A, T P M T^{*} 3 B$ and $T P M T^{*} 3 C$ were $0,0,0$ and $2.9 \%$, respectively (Table 2 ). The allele frequency of TPMT mutation in the SLE group was greater than that $(1.1 \%)$ of the healthy control in this study and any other reported value in Japanese healthy subjects. ${ }^{18-20)}$
Table 2. Allele Frequencies (\%) of TPMT Alleles in SLE Patients and in Control Individuals

\begin{tabular}{lccccc}
\hline \hline & TPMT*1 & $* 2$ & $* 3 A$ & $* 3 B$ & $* 3 C$ \\
\hline SLE patients $(n=68)$ & 97.1 & 0 & 0 & 0 & $2.9^{a)}$ \\
Healthy volunteer $(n=174)$ & 98.9 & 0 & 0 & 0 & 1.1
\end{tabular}

a) Not significantly different from that of the healthy control group $(p=0.23)$. Chisquare statistic $=0.99$.
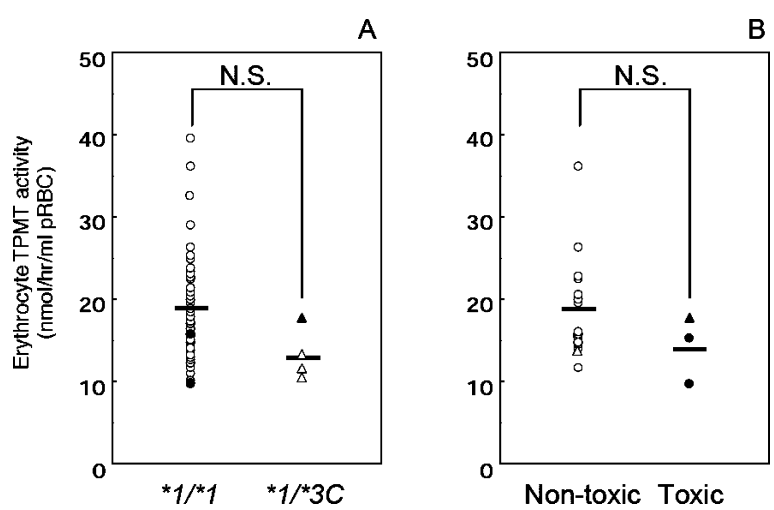

Fig. 1. (A) Comparison of TPMT Activity in Red Blood Cell from Patients with SLE Who Had the TPMT*1/*1 $(n=51)$ and TPMT*1/*3C $(n=4)$ Genotype and (B) TPMT Activity of AZA Treated Patients Who Had the $T P M T^{*} 1 / * 1 \quad(n=16)$ and $T P M T^{*} 1 / * 3 C(n=2)$ Genotype with $(n=3)$ and without $(n=15)$ Severe Leucopenia

(A) N.S., not significantly different $(p=0.11)$. (B) N.S., not significantly different $(p=0.32)$. Circles and triangles indicate patients who had the $T P M T^{*} 1 / *^{*} 1$ and $T_{P M T^{*}} 1 /^{*} 3 C$, respectively. Closed and open symbols indicate patients with and without leucopenia, respectively. The averages for each group are shown as a horizontal bar.

In the present study, mean value of TPMT activities in 51 subjects with $T P M T^{*} 1 / * 1(18.1 \pm 6.1 \mathrm{nmol} / \mathrm{h} / \mathrm{ml} \mathrm{pRBC})$ was $40 \%$ higher than that of 4 subjects with $T P M T^{*} 1 / * 3 C$ $(13.2 \pm 3.2 \mathrm{nmol} / \mathrm{h} / \mathrm{ml} \mathrm{pRBC})$ (Fig. 1A). Ten patients with $T_{P M T}^{*} 1 / * 1$ showed lower TPMT activity than the mean value in patients with $T P M T^{*} 1 / * 3 C$. Therefore, detection of the patients with low TPMT activity only by genotyping of TPMT is still imperfect.

Though the majority of our patients tolerated azathioprine well, azathioprine was withdrawn in a small number of patients because of leucopenia $(n=3$, Fig. 1B). Two out of 4 SLE patients with heterozygous $T P M T^{*} 3 C$ had been treated with AZA, and one patient showed a leucopenia (WBC $\left.2300 / \mathrm{mm}^{3}\right)$ after a 1 -month AZA $(50 \mathrm{mg} / \mathrm{d})$ therapy.

\section{DISCUSSION}

This report is, to our knowledge, the first to document the allele frequency and the enzymatic activity of TPMT in SLE patients, a candidate patient group who may undergo an AZA therapy.

Since the allele frequency of $T P M T^{*} 3 C$ did not reach a statistically significant difference between the SLE patient and healthy control groups $(p=0.23)$, we estimated a betaerror (or beta-power) of our study according to a chi-square test. $^{21,22)}$ If we decide to reject null hypothesis at a two-sided alpha-level of 0.05 with beta-level of 0.2 , the total number of the study subjects needed for a proposed research would be $546(>1091 / 2)$ for both the SLE and control groups. This was a difficult task for the proposed research, because such a 
large number of SLE patients could not be collected at our hospital. With this limitation in the study, the observed trend that the TPMT*3C allelic frequency $(2.9 \%)$ was greater in the SLE patient group compared with that $(1.1 \%)$ in the control group may be a chance observation.

Naughton et al. $^{23)}$ determined TPMT genotype in 120 patients with SLE in United Kingdom, and found one homozygote and five heterozygotes with $T P M T^{*} 3 A$ allele, and one heterozygote of $T P M T^{*} 3 C$. A patient with homozygous $T P M T^{*} 3 A$ allele in whom rapid bone marrow aplasia developed by AZA. Additionally, three heterozygotes had shown an excellent disease control by subtherapeutic dose of AZA $(25-150 \mathrm{mg} / \mathrm{d})$. In the yeast expression system, the TPMT activities of $T P M T^{*} 2, T P M T^{*} 3 A, T P M T^{*} 3 B$ and $T P M T^{*} 3 C$ mutant alleles showed $>100$-fold, $>100$-fold, 9-fold and 1.4fold lower than that with the wild-type, respectively. ${ }^{10,11)}$ When expressed in humans, the immunodetectable TPMT protein in $T P M T^{*} 3 C$ heterozygous individuals was about $50 \%$ lower than in homozygous wild-type individuals. ${ }^{24)}$ The TPMT activity of one subject with $T P M T^{*} 1 / * 3 C$ was $40 \%$ lower than the mean value of TPMT activities in 44 Japanese subject. ${ }^{9)}$ In the present study, the TPMT activity of subjects with $T P M T^{*} 1 / * 3 C(n=4$; men: 2 , women: 2$)$ was $30 \%$ lower than that of subjects with $T_{P M T}^{*} 1 / * 1 \quad(n=51$; men: 5, women: 46) (Fig. 1A). This result was consistent with the previous reports.

In our study, two out of 4 SLE patients with heterozygous $T P M T^{*} 3 C$ had been treated with AZA, and one patient

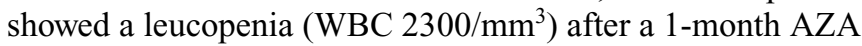
$(50 \mathrm{mg} / \mathrm{d})$ therapy, suggesting the likeliness that the TPMT pharmacogenetic assessment may be an important clinical tool for predicting an AZA-related toxicity. On the other hand, two patients with homozygous TPMT*1 showed hematopoetic toxicity, and TPMT activity of these patients is similar to that of TPMT*3C heterozygous (Fig. 1B). Since there is probably a variety of reasons of low TPMT activity and/or development of thiopurine toxicity, careful monitoring should be continued for the patients with wild type TPMT gene. $^{25)}$

In conclusion, the allele frequency of TPMT mutation in the Japanese SLE patient group was $2.9 \%$. The TPMT genotyping may be useful for Japanese SLE patient group to avoid the AZA-induced adverse events, although detection of the patient with low TPMT activity only by genotyping is still imperfect.

Acknowledgements We deeply appreciate the contribution of Dr. Richard Weinshilboum, Mayo Medical School and Dr. William Evans, St' Jude Children's Hospital, to our study who kindly provided DNA reference samples (TPMT*2 and TPMT*3A variants).

\section{REFERENCES}

1) Remy C. N., J. Biol. Chem., 238, 1078-1084 (1963).

2) Woodson L. C., Weinshilboum R. M., Biochem. Pharmacol., 32, $819-826$ (1983).

3) Schutz E., Gummert J., Mohr F., Oellerich M., Lancet, 341, 436 (1993).

4) McLeod H. L., Miller D. R., Evans W. E., Lancet, 341, 1151 (1993).

5) Escousse A., Rifle G., Sgro C., Mousson C., Zanetta G., Chevet D., Eur. J. Clin. Pharmacol., 48, 309-310 (1995).

6) Leipold G., Schutz E., Haas J. P., Oellerich M., Arthritis Rheum., 40, 1896-1898 (1997).

7) Weinshilboum R. M., Sladek S. L., Am. J. Hum. Genet., 32, 651-662 (1980).

8) Yates C. R., Krynetski E. Y., Loennechen T., Fessing M. Y., Tai H. L., Pui C. H., Relling M. V., Evans W. E., Ann. Intern. Med., 126, 608614 (1997).

9) Nishida A., Kubota T., Yamada Y., Higashi K., Kitamura K., Nakahara K., Iga T., Clin. Chim. Acta, 323, 147-150 (2002).

10) Szumlanski C., Otterness D., Her C., Lee D., Brandriff B., Kelsell D., Spurr N., Lennard L., Wieben E., Weinshilboum R., DNA Cell Biol., 15, 17-30 (1996).

11) Tai H. L., Krynetski E. Y., Yates C. R., Loennechen T., Fessing M. Y., Krynetskaia N. F., Evans W. E., Am. J. Hum. Genet., 58, 694-702 (1996).

12) Decaux G., Horsmans Y., Houssiau F., Desager J. P., Am. J. Ther, 8, $147-150$ (2001)

13) Tan E. M., Cohen A. S., Fries J. F., Masi A. T., McShane D. J., Rothfield N. F., Schaller J. G., Talal N., Winchester R. J., Arthritis Rheum., 25, 1271-1277 (1982).

14) Weinshilboum R. M., Raymond F. A., Pazmino P. A., Clin. Chim. Acta, 85, 323-333 (1978).

15) Jacqz-Aigrain E., Bessa E., Medard Y., Mircheva Y., Vilmer E., Br. $J$. Clin. Pharmacol., 38, 1-8 (1994).

16) Ganiere-Monteil C., Pineau A., Kergueris M. F., Azoulay C., Bourin M., J. Chromatogr. B, 727, 235-239 (1999).

17) Medard Y., Nafa S., Jacqz-Aigrain E., J. Chromatogr. B, 700, 275 277 (1997).

18) Kubota T., Chiba K., Br. J. Clin. Pharmacol., 51, 475-477 (2001).

19) Hiratsuka M., Inoue T., Omori F., Agatsuma Y., Mizugaki M., Mutat. Res., 448, 91-95 (2000).

20) Kumagai K., Hiyama K., Ishioka S., Sato H., Yamanishi Y., McLeod H. L., Konishi F., Maeda H., Yamakido M., Pharmacogenetics, 11, $275-278$ (2001).

21) Feinstein A. R., Clin. Pharmacol. Ther, 18, 491-505 (1975).

22) Freiman J. A., Chalmers T. C., Smith H., Kuebler R. R., N. Engl. J. Med., 299, 690-694 (1978).

23) Naughton M. A., Battaglia E., O’Brien S., Walport M. J., Botto M., Rheumatology, 38, 640-644 (1999).

24) Loennechen T., Yates C. R., Fessing M. Y., Relling M. V., Krynetski E. Y., Evans W. E., Clin. Pharmacol. Ther, 64, 46-51 (1998).

25) Aken J., Schmedders M., Feuerstein G., Kollek R., Am. J. Pharmacogenetics, 3, 149-155 (2003). 